\title{
Activismos corpocentrados. Estéticas de la resistencia alrededor de los cuerpos desaparecidos. Caso Ayotzinapa*
}

\author{
Activisms corpocentrados. Aesthetics of the resistance around the disappeared bodies. \\ Ayotzinapa Case
}

Ativismos corpocentrados. Estética da resistência em torno dos corpos desaparecidos.

\author{
Caso Ayotzinapa
}

Manuel Francisco González Hernández**
Universidad Nacional Autónoma de México, México.
Correo electrónico: fcogonlez@yahoo.com.mx

Revista Corpo-grafías: Estudios críticos de y desde los cuerpos / Volumen 5 - Número 5 / Enero - diciembre de 2018 /

ISSN impreso 2390-0288, ISSN digital 2590-9398 / Bogotá, D.C., Colombia / pp. 102-111.

Fecha de recepción: 24 de mayo de 2017

Fecha de aceptación: 9 de julio de 2017

Doi: https://doi.org/10.14483/25909398.14209

Cómo citar este artículo: González, M.F. (2018, enero-diciembre). Activismos corpocentrados. Estéticas de la resistencia alrededor de los cuerpos desaparecidos. Caso Ayotzinapa. Revista Corpo-grafías: Estudios críticos de y desde los cuerpos, 5(5), p-p 102-111 / ISSN 2390-0288.

*Artículo de investigación: resultado de las investigaciones del autor en el Doctorado en Estudios Latinoamericanos en la UNAM, cuya pregunta detonadora fue ¿Cómo es usado el cuerpo en las prácticas artísticas en las protestas por el caso Ayotzinapa y qué tipo de sujeto político puede emerger en el cruce de arte y activismo? En este artículo se utilizaron tres ejemplos concretos de prácticas estéticas que permitieron elaborar un breve análisis de la relación entre cuerpo, arte y activismo, cuya categoría central es el activismo corpocentrado. Parte de una metodología basada en las artes para reflexionar la relación entre las protestas sociales y su vínculo con las prácticas estéticas y la memoria latinoamericana entorno a las violencias políticas.

**Maestro en Artes Visuales por la Universidad Nacional Autónoma de México (UNAM), candidato a doctor en Estudios Latinoamericanos por la UNAM. Docente del programa de maestría en Desarrollo Educativo, línea de Educación Artística de la Universidad Pedagógica Nacional en convenio con el Centro Nacional de las Artes (CENART).

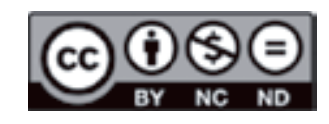




\section{Resumen}

En las protestas realizadas alrededor de la desaparición de 43 estudiantes normalistas de Ayotzinapa, México, se encuentra una amplia gama de propuestas de la imaginería artística y estética, cuyo centro de producción es el cuerpo, como medio o concepto. En dichas expresiones se encuentra una clara articulación entre el arte y el activismo, operan como formas de resistencia y protesta frente a un Estado que se señala como responsable de los hechos de violencia. Estas prácticas de corte estético son referidas como activismo corpocentrado porque el cuerpo es y se encuentra en el medio de la acción de protesta, es un tipo de activismo por la búsqueda de los cuerpos desaparecidos, la verdad y la justicia, su acción deviene en memoria.

Palabras clave: activismo artístico; Ayotzinapa; cuerpos desaparecidos; memoria.

\section{Abstract}

In the protests made around the disappearance of 43 students of Ayotzinapa, Mexico, there is a wide range of artistic and aesthetic imagery proposals, whose center of production is the body, as a medium or concept. In these expressions is a clear articulation between art and activism, operate as forms of resistance and protest against a State that is identified as responsible for acts of violence. These aesthetic practices are referred to as body-centered activism because the body is and is in the middle of protest action, it is a type of activism for the search of the disappeared bodies, truth and justice, its action becomes in memory.

Keywords: artistic activism; Ayotzinapa; disappeared bodies; memory.

\section{Resumo}

Nos protestos em torno do desaparecimento de 43 estudantes de Ayotzinapa, México, há uma ampla gama de propostas de imagens artísticas e estéticas, cujo centro de produção é o corpo, como um meio ou conceito. Nessas expressões há uma clara articulação entre arte e ativismo, operam como formas de resistência e protestam contra um Estado que é identificado como responsável por atos de violência. Essas práticas estéticas são chamadas de ativismo corpo-centrado porque o corpo é e está no meio da ação de protesto, é um tipo de ativismo que busca dos corpos desaparecidos, a verdade e a justiça, sua ação se torna em memória.

Palabras-chave: ativismo artístico; Ayotzinapa; corpos desaparecidos; memoria. 


\section{Introducción}

La desaparición de 43 estudiantes normalistas en Guerrero, México, la noche y madrugada entre el 26 y 27 de septiembre de 2014 , provocó la indignación social en el país y en el mundo entero, la cual se expresó en protestas territoriales y digitales, enmarcadas, en algunos casos, como "acciones globales por Ayotzinapa". En estas jornadas de protesta por los cuerpos desaparecidos han participado amplios sectores de sociedades que identifican el caso como un atentado contra el cuerpo social, "con las desapariciones individuales, es el cuerpo social el que está siendo nuevamente sustraído" (Massota, 2017).

A pocos meses ${ }^{1}$ de cumplirse cuatro años de los hechos de violencia perpetrados en contra de esta población estudiantil, las investigaciones realizadas no han dado los suficientes elementos para esclarecer los hechos, no hay señales de los estudiantes y las personas que han sido identificadas como responsables de los hechos, asentados en lo que se conoce como "la verdad histórica" ${ }^{2}$, se asume que fueron torturadas ${ }^{3}$ con el fin de arrancarles declaraciones sobre su supuesta participación. Esto complejiza más el caso y señala al Estado mexicano como parte de la maniobra de terrorismo y violencia a la que fueron expuestos los estudiantes.

A pesar de lo anterior, la participación social en la protesta no ha disminuido, hasta el día de hoy continúan las expresiones que claman verdad y justica, pero sobre todo las exigencias de presentación con vida de los normalistas, mismas que se han ampliado para otros desaparecidos, pues en México la desaparición de los cuerpos sigue siendo una constante de la vida social.

\section{Poner el cuerpo}

En las movilizaciones y protestas por la desaparición, participan actores diversos que acuden a formas de resistencia que toman como base de su acción, las demandas de los padres de los estudiantes y objetivos de visibilidad en el hacer, esto se expresa en repertorios que operan como la incorporación de la protesta, pues se observan dinámicas y acciones corporales. (González, 2015)

La incorporación de la protesta se refiere a posicionar el cuerpo como eje de acción, el cuerpo se exhibe en las acciones territoriales realizadas en el espacio público y se difunden vía los medios digitales e internet, principalmente las redes sociales, en algunos otros casos, se realizan convocatorias en el espacio digital para realizar acciones que se emplazan en geografías y espacios específicos, de esta manera las protestas por el cuerpo desaparecido y desde el cuerpo mantienen una convergencia entre lo territorial y lo digital. Estas acciones pueden considerarse como acciones estéticas porque recurren a formas sensibles para visibilizar la indignación por la desaparición de los cuerpos.

Queda de ejemplo el flashmob titulado "1 minuto por Ayotzinapa" realizado el 8 de noviembre de 2014, en la Plaza de la Constitución (Zócalo) de la capital mexicana, fue convocado vía internet por un grupo de bailarines. Los participantes, artistas, estudiantes y activistas se tiraron al piso de la plaza por un minuto, mientras sostuvieron las fotos de los estudiantes desaparecidos.

1 Han transcurrido 44 meses ( 3 años 8 meses) desde la desaparición de los estudiantes.

2 "La verdad histórica" es la supuesta verdad que emitió el entonces Procurador General de la Republica en 2014, basado en investigaciones que aseguraron que los estudiantes fueron asesinados por miembros del crimen organizado, sus cuerpos fueron calcinados en una gran fogata en un basurero de Cocula, Guerrero, y las cenizas se regaron en el Rio San Juan de dicha localidad. Esta "verdad" después sería desmentida por el Grupo de Expertos Interdisciplinarios Independientes GIEI.

3 Así lo señaló la Oficina del Alto Comisionado de las Naciones Unidad para los Derechos Humanos, en el documento Doble Injusticia. Informe sobre violaciones de derechos humanos en la investigación sobre el caso Ayotzinapa. 

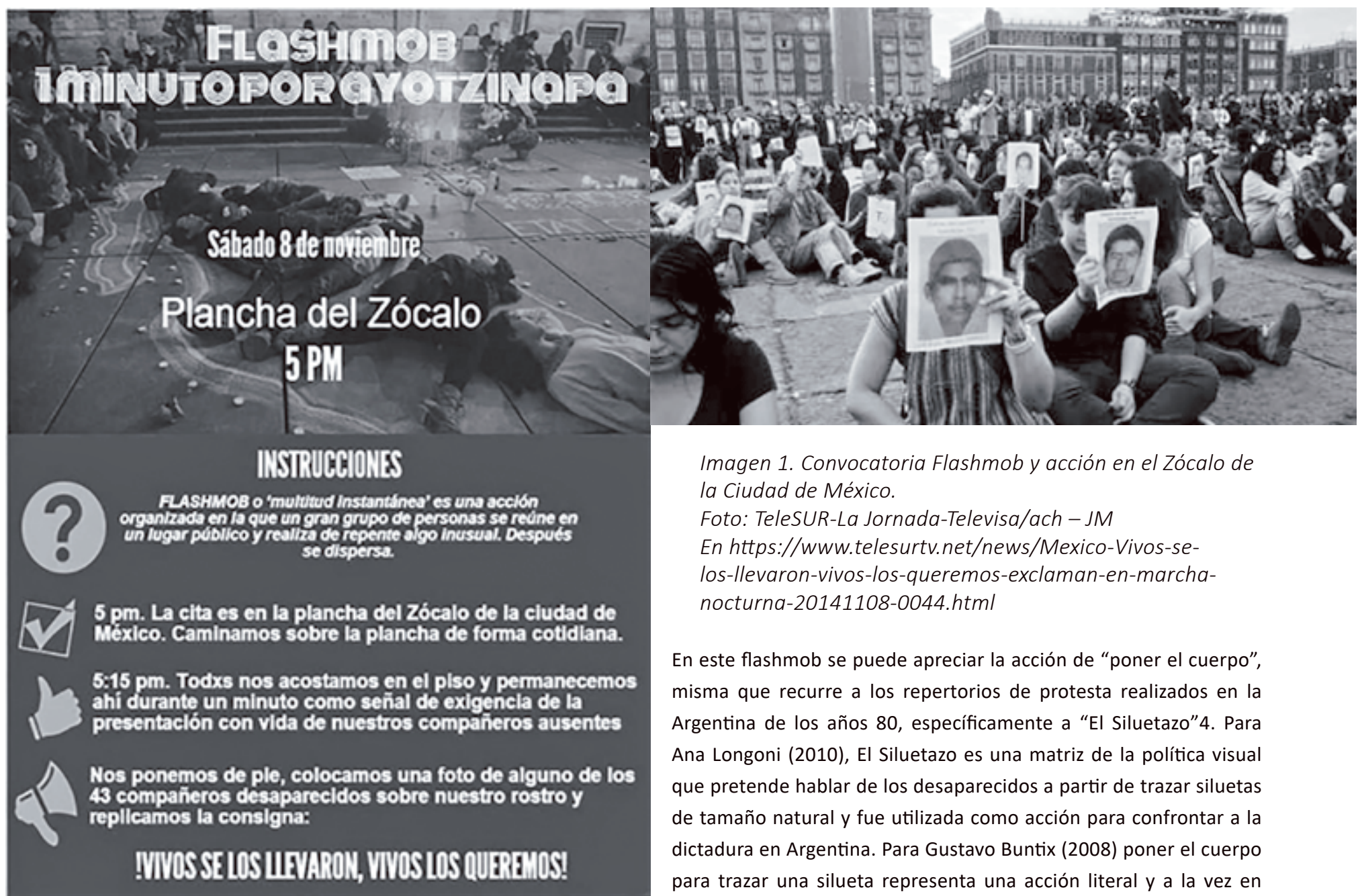

Imagen 1. Convocatoria Flashmob y acción en el Zócalo de la Ciudad de México.

Foto: TeleSUR-La Jornada-Televisa/ach - JM

En https://www.telesurtv.net/news/Mexico-Vivos-selos-llevaron-vivos-los-queremos-exclaman-en-marchanocturna-20141108-0044.html

En este flashmob se puede apreciar la acción de "poner el cuerpo", misma que recurre a los repertorios de protesta realizados en la Argentina de los años 80, específicamente a "El Siluetazo"4. Para Ana Longoni (2010), El Siluetazo es una matriz de la política visual que pretende hablar de los desaparecidos a partir de trazar siluetas de tamaño natural y fue utilizada como acción para confrontar a la dictadura en Argentina. Para Gustavo Buntix (2008) poner el cuerpo para trazar una silueta representa una acción literal y a la vez en sentido figurado, pues implica prestar el cuerpo para llenar un vacío.

En el flashmob que se menciona no hay propiamente el trazo de siluetas, sin embargo, sí encontramos la acción de poner el cuerpo de los manifestantes, ellos colocan sus cuerpos en la plaza, realizan una acción política y estética, con una fuerte carga ritual, que es efímera, pues solo dura un minuto, pero que continúa con la acción de dotar de identidad a cada uno de los desaparecidos mediante las fotografías de sus rostros y al nombrarlos por su nombre.

Ana Longoni (2010) asume que en la acción de poner el cuerpo: a) el que protesta ocupa momentáneamente el lugar del desaparecido, esto supone que cualquiera puede ser el desaparecido, b) es un acto de encarnación efímero, pues se devuelve la corporeidad al desaparecido, aunque sea momentáneamente, y c) se dota al desaparecido de una condición de sujeto.

4 El Siluetazo, tuvo lugar el 21 de septiembre de 1983 en Buenos Aires, durante la tercera marcha de la Resistencia convocada por las Madres de la Plaza de Mayo. La propuesta fue de los artistas visuales Rodolfo Aguerreberry, Julio Flores y Guillermo Kexel, que plantearon un "hecho gráfico" que sacudiera por su extensión física y por los recursos usados, para llamar la atención de la prensa y los medios de comunicación. 
El Siluetazo al igual que el Flashmob enunciado, operan como un hecho visual de corte participativo, en donde los colaboradores devienen en productores y con ello se diluye la participación de los artistas y de los convocantes, por ello, dice Roberto Amigo (1995) es una "acción estética de praxis política" porque los cuerpos de los participantes conforman un material estético colectivo que genera una postura política en contra de la desaparición, en suma es un discurso desde los cuerpos y lo visual.

Una vez concluido el minuto del flashmob, se levantaron y gritaron “iPorque vivos se los llevaron, vivos los queremos!” gritaron más consignas en contra del gobierno, principalmente la que refiere a "iFue el Estado!, al tiempo que señalaban el Palacio Nacional de Gobierno; la consigna de "Fue el Estado" será reiterativa en múltiples espacios de protesta.

\section{El cuerpo desentrañado}

Las acciones emprendidas en las protestas por la denuncia de la desaparición de los 43 estudiantes de la Escuela Normal Rural de Ayotzinapa son un llamado para dignificar los cuerpos desaparecidos, para exigir al Estado verdad y justicia, asimismo para convocar a una escucha social, una escucha que posibilite el hacer comunidad.

Una de las acciones más emblemáticas durante los primeros meses de la desaparición de los normalistas fue la realizada por el colectivo Rexiste $^{5}$, también en la Plaza de la Constitución en Ciudad de México, durante la marcha del día 20 de noviembre de 2014, consistió en escribir con letras gigantes la frase "FUE EL ESTADO", y después colocar en cada letra veladoras, con esta frase se responsabiliza al gobierno mexicano de los hechos de violencia y la desaparición de los estudiantes, un Estado que se ha señalado opera en fusión con el crimen organizado. La frase "Fue el Estado", en palabras de Cristina Rivera Garza (2015), refiere a un "Estado sin entrañas", un Estado que "rescinde su relación con el cuidado del cuerpo de sus constituyentes" (2015, p. 11), el Estado que identifica Rivera, es uno que se "lava las manos" que le da la espalda a sus compromisos y a sus responsabilidades, que se rinde a la lógica del capital, es decir, la ganancia, y que además se fusiona con el narco, fundando un narco gobierno.

5 El colectivo Rexiste se autodefine como un colectivo integrado por amigos que se conocieron en el movimiento Yo Soy 132, en el año 2012 . El nombre surge del juego de palabras "resiste" y "existe". El colectivo está interesado en la situación política y social del país, particularmente, en el tema de los derechos humanos, su trabajo se centra en la producción de esténcil, cartel y vídeo. La página de internet del colectivo es rexiste.org

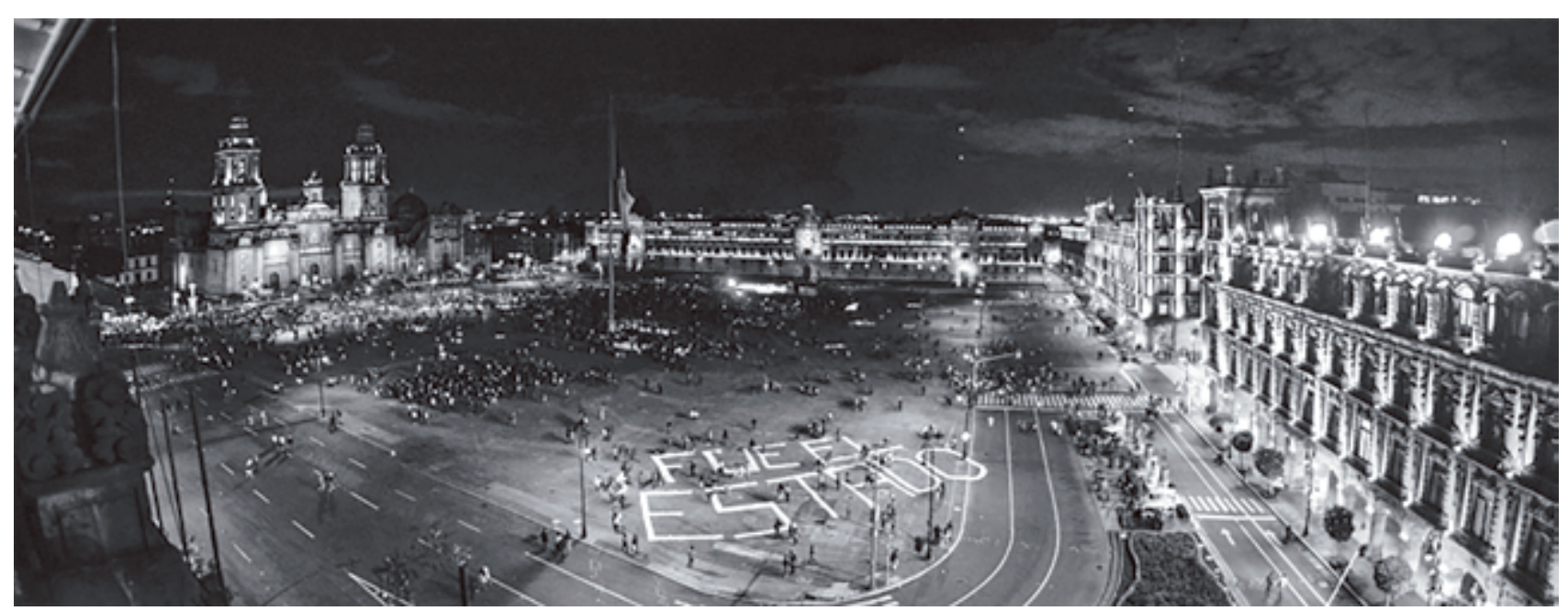

Imagen 2. Fue el Estado. Foto: Colectivo Rexiste

En línea: http://rexiste.org/post/107326632417/pinta-monumental-fue-el-estado-en-el-z\%C3\%B3calo-de 
El Estado sin entrañas utiliza la violencia y el terrorismo como medios de opresión, control y dominación, dotando a sus cuerpos policiales y militares de facultades para producir "cuerpos desentrañados" (Rivera, 2015, p.12), cuerpos considerados desechables, de segunda o tercera, cuerpos basura. Un Estado sin entrañas es también totalitario porque promueve el uso de la violencia y de la impunidad, un Estado que funda el horrorismo, (Tony Judt), por tanto, un Estado que promueve el terror. Para Rivera, el terror surge cuando el cuerpo tiembla y huye para conservar su vida.

\section{La urgencia estética}

Frente a los hechos de violencia en Iguala en septiembre de 2014, la sociedad mexicana enfrentó el terror, pero también el dolor, de esta manera dice Rivera Garza: "cuando todo enmudece, cuando la gravedad de los hechos rebasa con mucho nuestro entendimiento e incluso nuestra imaginación, entonces está ahí, dispuesto, abierto, tartamudo, herido, balbuceante, el lenguaje del dolor" (2015, p. 14).

Entonces, surge la necesidad e importancia de dolerse, de decir "tú me dueles", estas parecen ser las palabras que, tanto los participantes del flashmob y el Colectivo Rexiste, gritan en el espacio público, en la protesta social, les dicen a los padres de los normalistas y al país mismo. La frase "tú me dueles" es un llamado a la aparición con vida de los estudiantes, un llamado de indignación, y un llamado para restituir un Estado con entrañas.

"Tú me dueles" es también una forma de exigir "... que el Estado cumpla sus funciones, que responda por la protección de la ciudadanía, ciñéndose a una ética del ciudadano civil, se demanda en realidad otra relación política. Acaso, incluso, otro entendimiento de lo político en cuanto a tal". (Rivera, 2015, p.24). El dolerse también parece ser la forma en que Jean-Louis Deotté (2015) asume el papel que tiene que tomar México en cuanto a los hechos de violencia que día a día aparecen, pues considera que: "México debe afrontar el "acontecimiento" de la práctica terrorista de la desaparición conceptualizándola y estatizándola" (p. 34).

El dolerse es un llamado a la urgencia estética, como lo refiere Rivera Garza, el más básico y también el más desencajado de los lenguajes. La urgencia estética es por el dolor de un cuerpo desentrañado, está urgencia encarnada en el cuerpo que protesta es para participar en la reconfiguración de los visible, lo decible, lo pensable, hacia nuevas posibilidades de lo posible en la vida social, “...todos los que han colocado su cuerpo junto a otros cuerpos en el foro público de ciudades y pueblos nos dicen, con toda claridad, que el momento de imaginar otro régimen ha empezado ya" (Rivera, 2015, p.25).

Los cuerpos de la sociedad civil junto a los cuerpos de los padres de los normalistas, pugnan por la aparición con vida de los cuerpos desaparecidos; los cuerpos que protestas muestran una agencia social, es decir, su capacidad para producir su propia historia a través de estrategias, como pueden ser la resistencia, la negociación o en su caso la desobediencia, para exigir la restitución de un Estado con entrañas que posibilite nuevas formas de relación.

\section{Activismo artístico}

En los ejemplos señalados se encuentra un discurso para tomar el cuerpo, la palabra y la plaza, un llamado que se vuelve acción y desobediencia, y se sustenta en la urgencia estética del dolerse. La desobediencia como acción para confrontar al Estado, consiste en cruzar fronteras, la frontera del derecho y la justica, en la que se demanda la aparición de los cuerpos desaparecidos, pues mientras no haya cuerpo no hay delito jurídico que perseguir. 
Las prácticas de desobediencia encarnadas en la protesta y en los cuerpos de la sociedad civil apuntan al uso de la imaginación como detonador de formas del decir, del aparecer y del pensar, por tanto un "como si", la posibilidad de lo imposible. El "como si" opera como un fenómeno que juega un papel en la organización coherente de nuestra experiencia, y se concreta de manera más factible en las obras artísticas. El arte como posibilitador de experiencias estéticas es participe de la desobediencia, desde la organización por el llamado de urgencia estética, las comunidades artísticas se han hecho presentes tomando cuerpo, palabra y plaza.

En las protestas por el caso de Ayotzinapa han estado presentes formas artísticas y estéticas en la demanda de justicia, los colectivos se han organizado de distintas maneras para denunciar y mostrar su indignación por la violencia de Estado, señalando que fue el Estado el culpable de la desaparición de los normalistas. Los pintores, los ilustradores, los músicos, los cineastas, se organizaron para denunciar y señalar la violencia alrededor de los cuerpos desaparecidos, con ello trabajan por la memoria.

El sujeto social que aparece en estas manifestaciones recurre a las estrategias del arte, propone formas de protesta y desobediencia estéticas, basadas en la imaginación, en el "como si". Sus prácticas se despliegan entre el activismo y el arte, entre lo estético y lo político, entre lo emocional y lo sensible. Son prácticas de activismo artístico, artivismo.

El activismo artístico para Marcelo Expósito (2012) encuadra prácticas de intervención social en las que prima el activismo con una dimensión artística / estética, en el hay una conexión de prácticas que recurren a múltiples medios de producción. El activismo artístico refiere a "modos de producción de formas estéticas y de racionalidad que anteponen la acción social a la tradicional exigencia de la autonomía del arte que es consustancial al pensamiento de la modernidad europea" (Expósito, 2012, p.43). Surge en el periodo entre guerras y busca rescatar la máxima de las vanguardias: integrar arte y vida en la praxis, más allá de discursos teóricos y conceptuales.

Su producción se da en marcadas tensiones y cruce de fronteras con las instituciones y la institución artística, pues se desarrolla en sus márgenes y límites. Las intenciones políticas y sociales de las prácticas del activismo artístico, determina estos límites, entre el adentro y el afuera de la institución cultural.

Su inclusión en los movimientos sociales busca repensar el valor social del arte, poner el arte y sus herramientas al servicio de la protesta, más allá de cuestionar la problemática de qué se considera arte, está pregunta no tiene sentido para la práctica. Pareciera que los activistas no están interesados en confrontar a la institución artística sino a las formas hegemónicas de producción estética (Expósito, 2012).

El activismo artístico plantea una autonomía de las prácticas que va por encima de la institución, que recurre a los saberes de las artes, sus materiales, herramientas, conceptos, símbolos y repertorios con la intención de cumplir objetivos políticos y sociales. Se basa en estéticas relacionales e intersubjetivas y en las demandas del contexto social, es un trabajo situado y de trabajo colaborativo, en sí recurre a las potencias del arte participativo.

El arte es visto como un medio de lucha y protesta para producir política mediante formas estéticas, como dice Expósito (2012), “Potenciar la micropolítica de los cuerpos", en el sentir y la sensación en conjunto con la emoción, esto posibilita agenciamientos y subjetivaciones que las prácticas propician. En la experimentación y producción estética se da una modelación del movimiento social, se potencia la capacidad creativa e imaginativa de la sociedad. "La finalidad es literalmente social-política: producir mecanismos de subjetivación alternativos en una sociedad que "se crea" a sí misma como una sociedad política" (Expósito, 2012, p.49) El activismo artístico busca integrar públicos ajenos al sistema del arte y la cultura, por lo tanto, no distingue artistas de no artistas. 


\section{Activismo corpocentrado}

Otro ejemplo en el que se puede identificar una clara mención al cuerpo desaparecido desde un activismo artístico que parte del cuerpo, es el trabajo que realizó el artista oaxaqueño Francisco Toledo, titulado “43 Papalotes”. Él en colaboración con los trabajadores del taller de Arte y Papel de San Agustín Etla, elaboraron 43 papalotes $^{6}$, con los rostros grabados de los estudiantes normalistas, el objetivo de la propuesta, además de exigir verdad y justicia, fue continuar con la búsqueda de los desaparecidos.

Los papalotes como artefactos estéticos llevan los rostros de los normalistas, es una operación retórica a manera de sinécdoque, es decir, la parte por el todo, en donde el rostro nos refiere al cuerpo. El rostro en los papalotes retoma los repertorios utilizados a lo largo de los años sobre la desaparición, pues el rostro es el icono que nos permite referir a la identidad visual de los desaparecidos, asimismo es una prueba de existencia.

La propuesta de los papalotes retoma las tradiciones y rituales del día de muertos en Juchitán, México, en donde se asume que el papalote es un medio que permite que las almas de los difuntos regresen a la tierra, sin embargo, Toledo no considera que los normalistas estén muertos, sino que usa como metáfora el papalote para que los estudiantes regresen a casa.

El papalote es un artefacto que requiere de una acción corporal para poder volarse, es decir, quien lo manipula hace una serie de acciones como correr o caminar para hacer que el papalote se eleve y pueda volar, lo sujeta con una cuerda para que el viento pueda elevarlo y darle dirección. Así la propuesta de Toledo no solo consistió en elaborar los papalotes, sino que también convocó a la población de Oaxaca, México a una acción para poder volarlos.

Esta acción de volar papalotes es para la búsqueda, pero también de protesta, eje nodal de la propuesta artivista. Toledo llamó a la toma de conciencia sobre el caso y sobre todo a la no repetición de sucesos similares; los papalotes son un medio para hablar de discursos entorno a la desaparición como: "verte regresar" y "volver a casa", así se teje una trama de emociones que no solo son las de los padres y madres, sino también de la sociedad organizada. Es la exigencia del volver de los cuerpos.

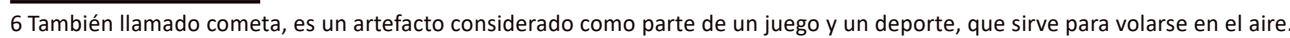

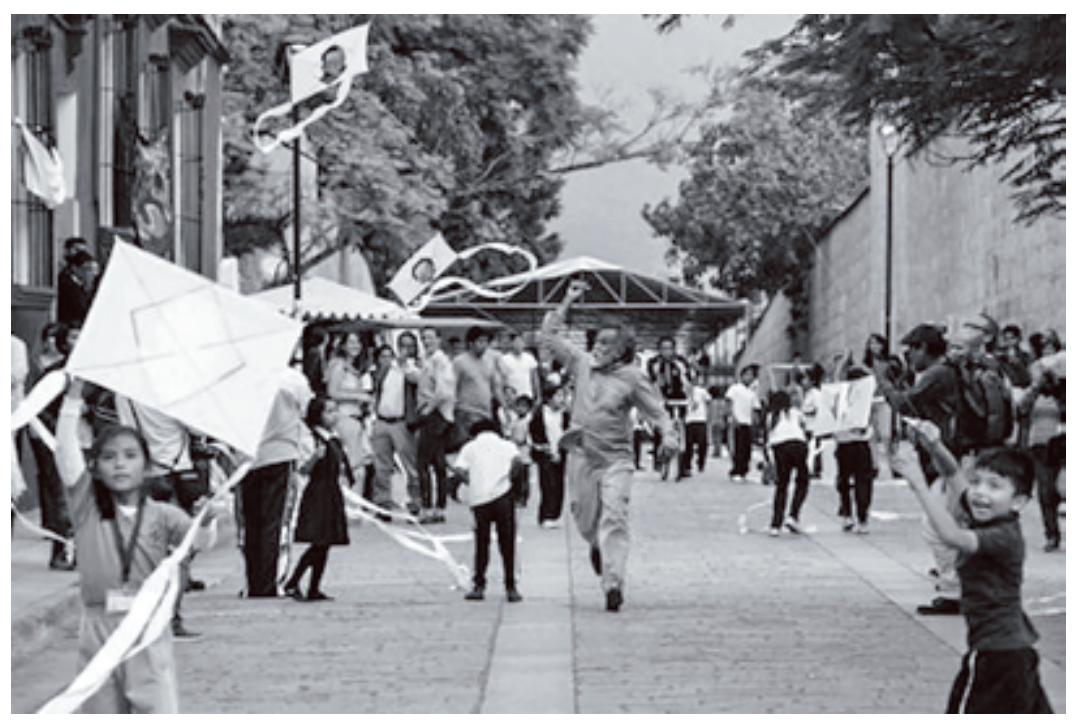

Imagen3. Toledo, niños y población volando los papalotes en Oaxaca.

Foto: J. A. Pérez

En http://www.fte-energia.org/E305/12.htm/ 
Los 43 papalotes como artefactos y la acción de volarlos nos permiten dimensionar un tipo de activismo desde las artes y desde el cuerpo, considerado como corpocentrado porque el cuerpo es el vector en su hacer, ya sea por su alusión, es decir, el rostro, o por su implicación directa, la acción de volarlo, como performance.

El activismo corpocentrado lo podemos identificar en cada uno de los tres ejemplos a los que se refiere en este texto, porque el cuerpo es la materia y el concepto de creación, al ponerlo como en el flashmob, al exigir justicia y señalar al Estado como responsable de su desaparición, en el caso de Rexiste o al aludirlo mediante su rostro y buscarlo, el caso de Toledo.

El cuerpo se encuentra en medio y es el medio en las acciones estéticas señaladas, porque representan las formas en que las artes son utilizadas para denunciar la desaparición de los normalistas, al tiempo que retoman repertorios de protesta que se han utilizado en otras geografías, del mismo modo, en este tipo de activismos corpocentrados, las artes operan como estrategias y herramientas de la acción política para evidenciar y denunciar la desaparición del cuerpo.

Ser un cuerpo, nos dice Judith Butler (2010), es estar expuesto a un modelo y a una forma de carácter social, por lo tanto la ontología del cuerpo, es una ontología de carácter social. La precariedad implica vivir socialmente, porque el hecho de que una vida está siempre en manos de otros, el ser cuerpo significa que se está expuesto a las fuerzas de lo social, así el cuerpo es un cuerpo vulnerable. Para Butler (2010) la vida excede las condiciones normativas, estas condiciones producen sujetos que no son reconocidos como sujetos, cuerpos desechables, que al ser desaparecidos y no tener posibilidad de un duelo, ponen en juego el reconocimiento de cuáles son las vidas que merecen ser lloradas y que importan.

Sin embargo, frente a las condiciones normativas marcadas por el Estado, aparece un llamado para exigir que esos cuerpos considerados como basura sean llorados, recordados y aparezcan, el llamado se libra en la esfera pública, construida en parte por lo que no puede ser dicho y lo que no puede ser mostrado, los límites de lo que puede aparecer son cruzados por el llamado de los padres de los normalistas apoyados por la sociedad civil y por la acción de los activistas artísticos que a partir imágenes y textos, exigen justicia por los estudiantes desaparecidos.

La propuesta de volar papalotes de Toledo es un acontecimiento en sí mismo, porque impacta, construye mirada y articula el afecto y el dolor, y hace un rescate de la memoria, es un devenir a la acción desde la vulnerabilidad de los cuerpos en la protesta social.

\section{Hacer memoria}

Las prácticas estéticas a las que he referido en este texto además de ser un medio para la denuncia, la exigencia de verdad y justicia, y la búsqueda de los desaparecidos, operan como medios para la memoria, pues como nos dice Elizabeth Jelin (2002) "Las víctimas y los sufrimientos provocados socialmente se canalizan y toman forma en acciones públicas de distinto orden, de tal manera que la creación artística, opera como un medio para incorporar y trabajar sobre el pasado y su legado" (2002, p.2). Estas formas estéticas son formas que estructuran la memoria colectiva porque maniobran desde el recuerdo y en diálogo con otros sucesos de violencia en la geografía latinoamericana, por tanto, instituyen memoria. 
Las prácticas de activismo artístico en la protesta social por la desaparición de los 43 son un llamado desde la urgencia estética y la crisis social; los activistas artísticos exhiben nuevas formas gramaticales y poéticas, formas de interrupción e intervención desde la desobediencia; es un llamado a la vida, es una forma de visibilizar e instalar memoria, que busca cuestionar al Estado e interpelar a la sociedad sobre la situación de vida en un Estado sin entrañas.

En el señalamiento de "Fue el Estado", se teje una suerte de activismo estético y emocional, que recurre a las herramientas de las artes y pone en juegos formas del decir, del aparecer y del pensar, para así protestar alrededor de los cuerpos de los normalistas desparecidos, estás acciones activistas nos hablan de un desvío de la norma, de una desobediencia que se libra en el espacio público, que proponen otras formas de relaciones política entre la sociedad y el Estado.

La confrontación, que se libra en el espacio público, está enmarcada por una urgencia estética, por el dolerse, por la búsqueda del nosotros y el reconocimiento de la vulnerabilidad y sentido de vida, los artistas acompañan desde los lenguajes artísticos para proponer un duelo colectivo y un "nosotros" que demanden al Estado nuevas formas de relaciones políticas. Estas demandas se hacen desde la desobediencia, desde un activismo corpocentrado, ya que el cuerpo es el centro de toda acción política y desde los lenguajes del arte se entretejen estrategias políticas, estéticas y artísticas en pro de la restitución de un Estado con entrañas.

\section{Referencias}

Amigo, R. (1995). “Aparición con vida: Las siluetas de detenidos-desaparecidos", en XVIII Coloquio Internacional de Historia del Arte, México, Instituto de Investigaciones Estéticas, UNAM, pp. 259-288.

Buntinx, G. (2008). “Desapariciones Forzadas / Resurrecciones Míticas”, en Longoni, A. y Bruzzone, G. (Comp.), (2008) El Siluetazo, Buenos Aires: Adriana Hidalgo (Ed.).

Butler, J. (2010). Marcos de Guerra. Vidas Iloradas. España: Editorial Paidós.

Expósito, M. (2012). "Activismo Artístico en Red Conceptualismos del Sur" (ed.) Perder la forma humana. Una imagen sísmica de los años ochenta en América Latina, Madrid: Museo Nacional Centro de Arte Reina Sofía.

Deotté, J. (2015). México: el desafío estético de la desaparición forzada, en CUHSO, Cultura, Hombre, Sociedad, 25(1), pp.33-45. En línea: http://cuhso.uct.cl/index.php/cuhso/article/viewFile/900/pdf_13

González Villareal, R. (2015). Ayotzinapa, la rabia y la esperanza. México: Editorial Terracota.

Jelin, E. (2002). Los trabajos de la memoria. Madrid: Siglo XXI Editores.

Longoni, A. (2010). Fotos y siluetas: Políticas visuales en el movimiento de derechos humanos en Argentina, en: Afteraal Jornal, 25, Universidad Internacional de Andalucía.

Rivera, C. (2015). Dolerse. Textos desde un país herido. México: Surplus Ediciones.

Massota, C. (2017). Retratos y desaparición. Comunidad Revista Anfibia, Destacados/Sociedad. En línea: http://comunidad.revistaanfibia.com/retratos-y-desaparicion/ 